obstetrics, and it seems that this opportunity is not being fully used.

If general practitioners' responsibility for intrapartum care continues to decline then the relative lack of general practitioners' participation in liaison committees and perinatal mortality meetings, as is found now in consultant units, is the most likely pattern in the future. It is only through such bodies that general practitioners are likely to be able to influence care at any stage of pregnancy and to exercise any advocacy role. We may be witnessing not only the terminal decline of general practitioner intrapartum care but also the start of a long process in which general practitioners are excluded from having any say in obstetric care.

We thank Mr A O Hughes for statistical advice and Mrs J James for preparing the questionnaire. This work was supported by a grant from the Scientific Foundation Board of the Royal College of General Practitioners. LFPS is a research training fellow of the Royal College of General Practitioners.
2 Royal College of Obstetricians and Gynaecologists and the Population nvestigation Committee. Maternity in Great Britain. Oxford: Oxford University Press, 1948.

3 Campbell R, MacFarlane A. Where to be born? The debate and the evidence. Oxford: National Perinatal Epidemiology Unit, 1987.

4 Marsh GN, Cashman HA, Russell IT. General practitioner participation in intranatal care in the Northern region in 1983. BMf 1985;290:971-3.

5 Office of Population Censuses and Surveys. Birth statistics. London: HMSO 1988.

6 Bryce FC, Clayton JK, Rand RJ, Beck I, Farquharson DIM, Jones SE General practitioner obstetrics in Bradford. BMf 1990;300:725-7.

Lowe SW, House W, Garrett T. Comparison of outcome of low-risk labour in an isolated general practitioner maternity unit and a specialist maternity hospital. I R Coll Gen Pract 1987;37:484-7.

8 Prentice A, Walton SM. Outcome of pregnancies referred to a general practitioner unit in a district general hospital. BMf 1989;299:1090-2.

Young G. Are isolated maternity units run by general practitioners dangerous? BMY 1987;294:744-6.

10 Cavenagh AJM, Phillips KM, Sheridan B, Williams EMJ. Contribution of isolated general practitioner maternity units. $B M \mathcal{J}$ 1984;288:1438-40.

11 Sangala V, Dunster G, Bohin S, Osborne J. Perinatal mortality rates in isolated general practitioner maternity units. BMF 1990;301:418-20.

12 Royal College of Obstetricians and Gynaecologists. Report on the RCOG working party on antenatal and intrapartum care. London: RCOG, 1982.

13 Rosenblatt RA, Reinken J, Shoemack P. Is obstetrics safe in small hospitals? Lancet 1985; ii:429-32.

14 Royal College of Obstetricians and Gynaecologists and Royal College of General Practitioners. Report on training for obstetrics and gynaecology for general practice, a joint working party. London: RCOG, 1981 .
Epidemiology, Department

of Public Health and

Primary Care, University of

Oxford, Headington,

Oxford OX3 7LF

Christine Sellar, PHD, research officer

Joyce A Ferguson, PHD, national health fellow

(Canada)

Michael J Goldacre, FFCM, director

Correspondence to: Dr Sellar.

\title{
Occurrence and repetition of hospital admissions for accidents in preschool children
}

\author{
Christine Sellar, Joyce A Ferguson, Michael J Goldacre
}

\section{Abstract}

Objectives-To examine trends over time in the rates of admission to hospital for accidents of preschool children and to study patterns of repeated admissions for accidents in these children.

Design-Analysis of linked, routine abstracts of hospital inpatient records for accidents.

Setting-Six districts in the Oxford Regional Health Authority covered by the Oxford record linkage study.

Subjects-Records for 19427 children aged 5 years and under at the time of first recorded admission to hospital.

Main outcome measure-Number of admissions to hospital.

Results-Records were analysed in three groups: person based annual admission rates were calculated for each calendar year; each child's first recorded admission in 1976-85 was identified, and the child's record was followed up by linkage for one year from that admission; each child's first recorded admission in 1976-81 was identified and followed up for five years. Overall, 19427 children from an average annual resident population of 163000 children in 1976-86 had 20657 admissions for accidents before they were 6 years of age. Of these admissions 13983 were for injuries, 5717 for poisonings, and 957 for burns. Admission rates declined after 1976 for poisoning, but no substantial changes over time were found in admission rates for injuries or burns. A total of 17724 children were followed up for one year and 10889 for five years; $470(2.6 \%)$ of the children who were followed up for one year and $926(8.5 \%)$ of those followed up for five years had at least one further admission for an accident. Of those followed up for one year the 4 and 5 year old children were least likely and those under 1 and 1 year old were most likely to have a further admission for an accident. The number of children who had more than one accident was greater than would be expected if accidents were random occurrences. Those who had a poisoning at first admission were more likely to have another poisoning than an injury or burn; and those who had a burn at first admission were more likely to have another burn.

Conclusions-Hospital admissions for accidents in children are common: on average 1 child in 88 in this population was admitted each year. Multiple admissions are uncommon but none the less occur more often than would be expected by chance.

\section{Introduction}

Among children aged 1-14 years accidents are the commonest cause of death and account for one fifth of all hospital admissions in the United Kingdom. There is currently a high level of interest in efforts to reduce the incidence of accidents in childhood..$^{1-4}$

Many studies have been carried out to identify whether some children are at a greater risk of accidents than others. Studies of accident proneness, for example, have examined the characteristics of children who had more than one accident, their behaviour, ${ }^{56}$ families, and environment. ${ }^{57}$ There is evidence that children who have had an accident are at greater risk of a further accident than other children $^{89}$ and that admissions to hospital for injury in preschool children may help predict admission for injury in the next five years. ${ }^{10}$ An earlier study using data from the Oxford record linkage study showed that a study of admission rates and subsequent admissions analysed by type of accident would be useful ${ }^{8}$

We examined trends in admission rates over time among preschool children, the group at greatest risk of poisonings, burns, and home injuries, ${ }^{11}$ and describe here the occurrence and repetition of accidents. The term accident is used generically to include injuries, burns, and poisonings.

\section{Subjects and methods}

The Oxford record linkage study is a collection of brief abstracts of hospital inpatient records together with data from birth and death certificates. ${ }^{12}$ Data have 
been collected for the study since 1963 , and by 1975 data collection covered six of the eight districts in the Oxford Regional Health Authority. The average annual population in the six districts between 1976 and 1986 was 1.9 million people including 163000 children aged $0-5$ years. The data presented here are based on records of patients who were both resident and treated in the six districts from 1976 to 1986.

Children aged 5 years and under were included in the study if they had a hospital admission during 1976-86 with "accident" or "emergency" as the recorded source of admission and with the main diagnosis on the discharge abstract in chapter 17 of the international classification of diseases. This chapter covers injury and poisoning. The codes used were N800-N989 and N996 in the eighth revision ${ }^{13}$ and codes 800-904 and 910-989 in the ninth revision ${ }^{14}$ of the classification. Accidents were grouped under three broad categories according to diagnosis - that is, injuries, burns, and poisonings.

TABLE I-Hospital admissions for injuries, poisonings, and burns in preschool children in the Oxford region 1976-86. Figures are numbers and average annual rates/1000 children of each sex aged 5 years and under

\begin{tabular}{|c|c|c|c|c|c|c|}
\hline \multirow{2}{*}{$\begin{array}{l}\text { Diagnostic } \\
\text { category }\end{array}$} & \multicolumn{2}{|c|}{ Boys } & \multicolumn{2}{|c|}{ Girls } & \multicolumn{2}{|c|}{ Total } \\
\hline & No & Rates & No & Rates & No & Rates \\
\hline Injuries & 7843 & $8 \cdot 5$ & 5956 & $6 \cdot 8$ & 13799 & $7 \cdot 7$ \\
\hline Poisoning & 3228 & $3 \cdot 5$ & 2443 & $2 \cdot 8$ & 5671 & $3 \cdot 2$ \\
\hline Burns & 601 & $0 \cdot 7$ & 348 & $0 \cdot 4$ & 949 & 0.5 \\
\hline Total & 11608 & 12.6 & 8707 & $10 \cdot 0$ & 20315 & $11 \cdot 3$ \\
\hline
\end{tabular}

Each child may appear in more than one diagnostic category in any year.
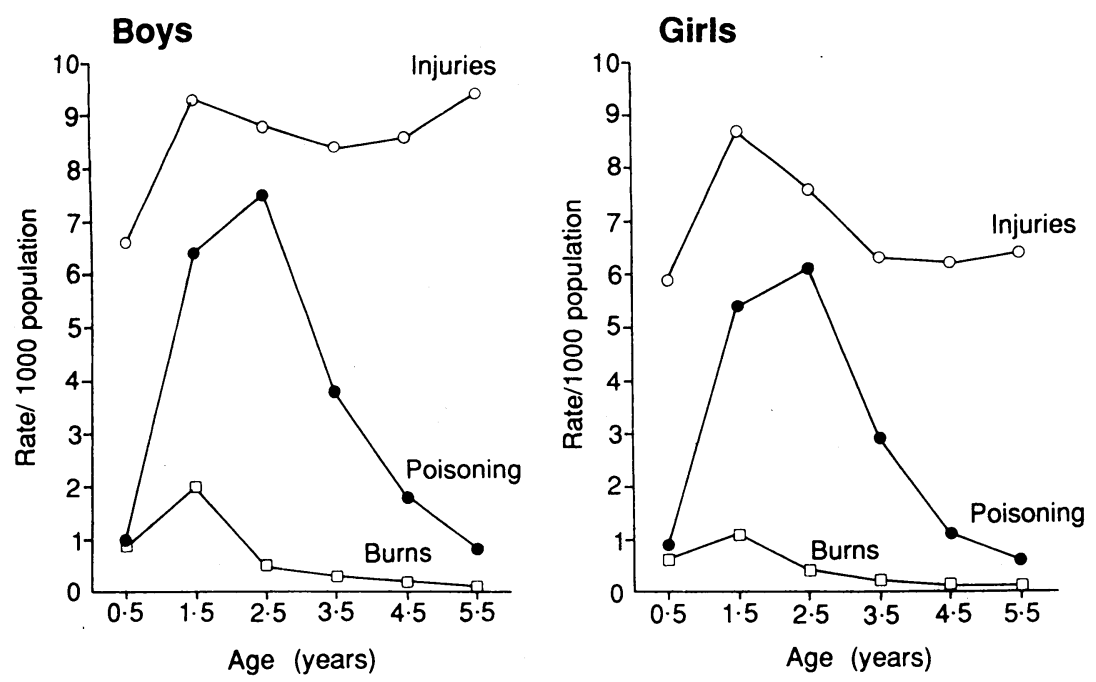

FIG 1-Average annual person based admission rates for 1976-86 by age and diagnostic category
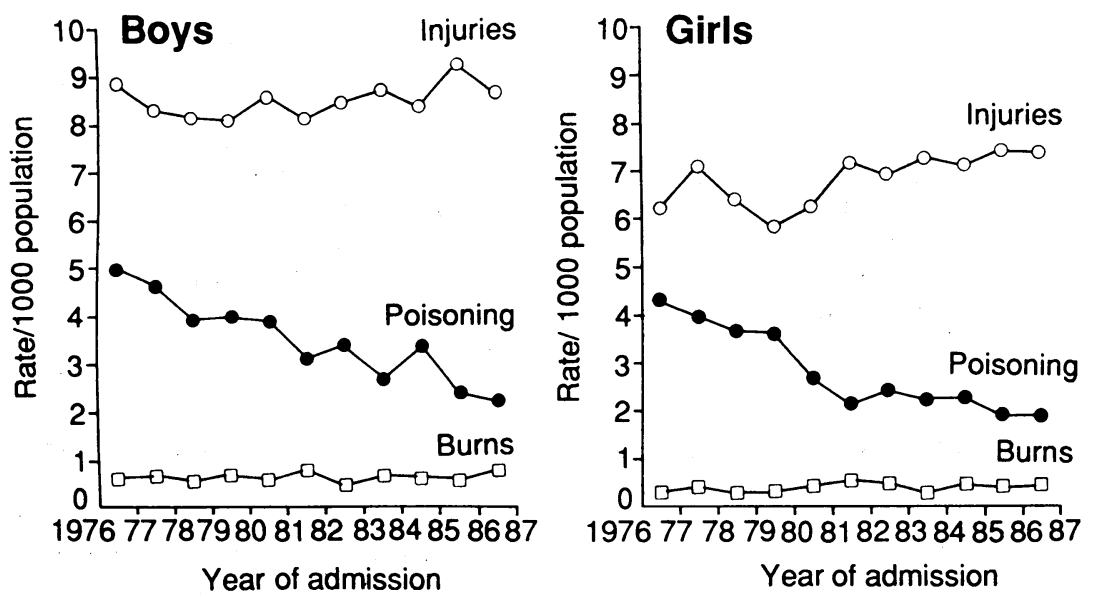

FIG 2-Age standardised person based admission rates for children aged 0-5 years by diagnostic category, year of admission, and sex
Population data for each single year of age are not available for the six districts. Population estimates were therefore derived by applying the proportions of children under 6 years in each single year age band in the population of England and Wales to the quinquennial population figures for the six districts.

Records were analysed in three main groups. Firstly, all admissions among children aged 5 years and under in 1976-86 were analysed, and person based annual admission rates were calculated for each calendar year. In these calculations each child was counted once in each year regardless of his or her number of admissions for accidents in the year. These data thus provide information on numbers and rates of children who were admitted for accidents during the year. The percentage change per year in admission rates from 1976 to 1986 and its $95 \%$ confidence intervals were calculated by logistic regression using generalised linear interactive modelling. Secondly, each child's first recorded admission during 1976-85 was identified and the child's record was followed up by linkage for one year from that admission. In this way we quantified the extent of repeated admissions within a year after the index admission. Thirdly, each child's first recorded admission between 1976 and 1981 was identified and the child's record was followed up for five years from the admission to quantify the extent of repeated admissions within this period. All records of further admissions were included in the analysis, including those when the children were over the age of 5 years, for the full duration of follow up.

In the analyses of repeated admissions hospital admission records for 1975 were examined to ensure that all first accidents occurred after at least one year without a previous accident. We also excluded as repeat admissions any records of admission which occurred 28 days or less after discharge from the index admission. We did this because of the possibility that short term readmission may have been for the same accident. We also identified all death records after the index admission in both the one and five year follow up cohorts. The $\chi^{2}$ test for trends in proportions was used to test the changes over time in the proportion of children who had more than one accident. ${ }^{15}$ Expected numbers of admissions per child were estimated using a Poisson distribution. ${ }^{15}$

\section{Results}

Between 1976 and 1986, 19427 children aged 5 years or under were admitted to hospital after an accident. Over the period of the study they had a total of 20657 admissions for accidents before they were 6 years of age. Of these episodes 13983 were for injuries, 5717 for poisonings, and 957 for burns.

\section{ADMISSION RATES}

Admission rates were highest for injuries and lowest for burns in both sexes and across all ages up to 5 years (fig 1). Admission rates for burns were highest in children aged 1 year and those for poisoning were highest at 1 and 2 years of age. Average annual person based admission rates were higher in boys than girls at each age from 0 to 5 years and for each of the three diagnostic categories (table I). We tested these differences comparing boys with girls within each single age band. Rates for boys were appreciably greater than rates for girls except in children aged 3 years and over admitted with burns and children under 1 year admitted with poisoning.

Figure 2 shows that there was a striking decline in admission rates between 1976 and 1986 for children admitted for poisoning but no substantial changes over time were found in admission rates for children admitted for injuries or burns. The data in this figure 
were age standardised by applying single year rates within the age group to take account of changes in the age distribution over time within the group. The decline in admission rates for poisoning was evident in each age band for both sexes and was significant in all cases except girls aged under 1 year. The overall annual percentage decline was $7 \cdot 7 \%$ (95\% confidence interval -8.5 to $-6.9 ; \chi^{2}$ trend $\left.=367 ; \mathrm{p}<0.01\right)$. Although the increase in admission rates for injuries was not substantial (less than $1 \%$ annually), it was significant $\left(\chi^{2}\right.$ trend $=13.55 ; \mathrm{p}<0.01)$. The increase was due to a small increase in the rates for girls, of $1.7 \% /$ year $(95 \%$ confidence interval 0.9 to $2 \cdot 5 ; \chi^{2}$ trend $=17 \cdot 7 ; \mathrm{p}<0.01$ ).

\section{REPETITION OF ADMISSION}

Records of 17747 children who had an index admission in 1976-85 were followed up for one year from that admission. Of these, 23 children died in the index admission and were excluded from the analysis of repetition. Within the year 17254 of the remaining 17724 children $(97 \cdot 3 \%)$ had no further admission (table II). Of the remainder $448(2 \cdot 5 \%)$ had two admissions for accidents, $20(0 \cdot 1 \%)$ had three, and two $(0.01 \%)$ had four accidents within the year. From 1976 to 1985 there was no significant change in the proportion who had a further admission when followed up for one yecr.

TABLE II-Hospital admissions for accidents/child when followed up for one year from first admission in 1976-85. Figures are number of admissions/child (percentage of children with each number of admissions)

\begin{tabular}{|c|c|c|c|c|c|}
\hline \multirow{2}{*}{$\begin{array}{l}\text { Diagnostic category } \\
\text { at first admission }\end{array}$} & \multicolumn{4}{|c|}{ No of admissions/child } & \multirow[b]{2}{*}{ Total } \\
\hline & 1 & 2 & 3 & 4 & \\
\hline Injuries & $11539(97 \cdot 4)$ & $299(2 \cdot 5)$ & $12(0 \cdot 1)$ & 2 & $11852(100 \cdot 0)$ \\
\hline Poisoning & $4921(97 \cdot 2)$ & $135(2 \cdot 7)$ & $5(0 \cdot 1)$ & & $5061(100 \cdot 0)$ \\
\hline Burns & $794(97.9)$ & $14(1 \cdot 7)$ & $3(0 \cdot 4)$ & & $811(100 \cdot 0)$ \\
\hline Total & $17254(97 \cdot 3)$ & $448(2 \cdot 5)$ & $20(0 \cdot 1)$ & 2 & $17724(100 \cdot 0)$ \\
\hline
\end{tabular}

Overall, 10905 children had an index admission between 1976 and 1981, and data on these were followed up for five years. Of these, 16 children died in the index admission and were excluded from further analysis. Of the remaining 10889 children, $926(8 \cdot 5 \%)$ had at least one further admission during the five years (table III). A further $816(7 \cdot 5 \%)$ had only one further admission, $89(0.8 \%)$ had three admissions, and 21 $(0 \cdot 2 \%)$ had four admissions or more in the five years.

TABLE III - Hospital admissions for accidents/child when followed up for five years from first admission in 1976-81. Figures are number of admissions/child (percentage of children with each number of admissions)

\begin{tabular}{|c|c|c|c|c|c|c|c|c|}
\hline \multirow{2}{*}{$\begin{array}{l}\text { Diagnostic } \\
\text { category } \\
\text { at first admission }\end{array}$} & \multicolumn{7}{|c|}{ No of admissions } & \multirow[b]{2}{*}{ Total } \\
\hline & 1 & 2 & 3 & 4 & 5 & 6 & 7 & \\
\hline Injuries & $6338(91 \cdot 2)$ & $532(7 \cdot 7)$ & $67(1 \cdot 0)$ & $10(0 \cdot 1)$ & 1 & 2 & 1 & $6951(100 \cdot 0)$ \\
\hline Poisoning & $3183(92 \cdot 3)$ & $241(7 \cdot 0)$ & $19(0 \cdot 6)$ & $6(0 \cdot 2)$ & 1 & & & $3450(100 \cdot 0)$ \\
\hline Burns & $442(90 \cdot 6)$ & $43(8 \cdot 8)$ & $3(0 \cdot 6)$ & & & & & $488(100 \cdot 0)$ \\
\hline Total & $9963(91 \cdot 5)$ & $816(7 \cdot 5)$ & $89(0 \cdot 8)$ & $16(0 \cdot 1)$ & 2 & 2 & 1 & $10889(100 \cdot 0)$ \\
\hline
\end{tabular}

For both the one and five year follow up periods the proportion of children who had a further admission did not vary significantly by diagnostic category at first admission. The proportion who had more than one admission in a year differed significantly by age at first admission $\left(\chi_{5}^{2}=50.3 ; p<0.01\right)$. Children aged 1 year and under were most likely and those aged 4 and 5 years were least likely to have a further admission within the year. The percentages of girls who had at least one further admission for an accident within a year of the first were, for those aged under $1,1,2,3,4$, and 5 years, respectively, $3 \cdot 6 \%, 3 \cdot 4 \%, 2 \cdot 8 \%, 2 \cdot 0 \%$, $1.4 \%$, and $1 \cdot 1 \%$. The corresponding figures for boys were $3 \cdot 7 \%, 3 \cdot 9 \%, 2 \cdot 2 \%, 2 \cdot 7 \%, 1 \cdot 6 \%$, and $1 \cdot 7 \%$.
The number of accidents per child in the population when modelled using a Poisson distribution showed that the number of children who had two or more accidents was greater than would be expected by chance (table IV). For example, if the chance of a

TABLE IV-Distribution of counts of admissions for accidents for preschool children when followed up for one year from index admission

\begin{tabular}{lrrrrr}
\hline \multirow{2}{*}{$\begin{array}{l}\text { No of } \\
\text { admissions/child }\end{array}$} & \multicolumn{2}{c}{ No of boys } & & \multicolumn{2}{c}{ No of girls } \\
\cline { 2 - 3 } \cline { 5 - 6 } \cline { 5 - 6 } & Observed & Expected $^{\star}$ & & Observed & Expected $^{\star}$ \\
\hline & 823974 & $823750 \cdot 1$ & & 782765 & $782598 \cdot 4$ \\
2 & 9880 & $10313 \cdot 1$ & & 7397 & $7721 \cdot 4$ \\
3 & 260 & $64 \cdot 6$ & & 188 & $38 \cdot 1$ \\
4 & 13 & $0 \cdot 3$ & & 1 & $0 \cdot 1$ \\
\hline Total & 1 & & & 1 & \\
\hline
\end{tabular}

${ }^{\star}$ Calculated using Poisson distribution.

$\dagger$ Total person years 1976-85.

second or third admission was a random occurrence the expected number of boys with two admissions would be 65 and the expected number of boys with three admissions would be one. In the study 260 boys were observed with two admissions and 13 boys had three. This was also true for each diagnostic category at index admission.

Among the 11873 children followed up for one year whose first accident was an injury $234(74 \cdot 8 \%)$ had an injury on second admission (table V). This was not

TABLE v-Distribution of first admissions in 1976-85 by diagnostic category and distribution of second admissions within one year in children first admitted with injuries, poisoning, and burns. Figures are numbers (percentages) of admissions

\begin{tabular}{|c|c|c|c|c|}
\hline \multirow[b]{2}{*}{$\begin{array}{l}\text { Diagnostic } \\
\text { category }\end{array}$} & \multirow[b]{2}{*}{$\begin{array}{c}\text { First } \\
\text { admission }\end{array}$} & \multicolumn{3}{|c|}{ Second admission $\star$} \\
\hline & & $\begin{array}{c}\text { Injury } \\
\text { as first } \\
\text { admission }\end{array}$ & $\begin{array}{l}\text { Poisoning } \\
\text { as first } \\
\text { admission }\end{array}$ & $\begin{array}{c}\text { Burn } \\
\text { as first } \\
\text { admission }\end{array}$ \\
\hline $\begin{array}{l}\text { Injuries } \\
\text { Poisoning } \\
\text { Burns }\end{array}$ & $\begin{array}{r}11873(66 \cdot 9) \\
5063(28 \cdot 5) \\
811(4 \cdot 6)\end{array}$ & $\begin{array}{r}234(74 \cdot 8) \\
69(22 \cdot 0) \\
10(3 \cdot 2)\end{array}$ & $\begin{array}{c}68(48 \cdot 6) \\
66(47 \cdot 1) \\
6(4 \cdot 3)\end{array}$ & $\begin{array}{l}4(23 \cdot 5) \\
5(29 \cdot 4) \\
8(47 \cdot 1)\end{array}$ \\
\hline Total & $17747(100 \cdot 0)$ & $313(100 \cdot 00)$ & $140(100 \cdot 00)$ & $17(100 \cdot 00)$ \\
\hline
\end{tabular}

*In the 470 children (table II) who had more than one admission within one year of their first admission.

substantially different from inat expected given the distribution of first accidents. The children who had a first admission for poisoning, however, were much more likely than others to have a poisoning on their second admission: $66(47 \cdot 1 \%)$ were admitted with poisoning at the second admission compared with 5063 $(28.5 \%)$ of the 17747 first admissions $\left(\chi_{2}^{2}=24 \cdot 1\right.$; $\mathrm{p}<0.01$ ). Children with burns as a first admission were also more likely to have a second accident that was a burn: eight $(47 \cdot 1 \%)$ of the 17 children who had a further admission were admitted with burns compared with $811(4.6 \%)$ of the 17747 first admissions $\left(\chi_{2}^{2}=69 \cdot 6\right.$; $\mathrm{p}<0.01)$. As children were followed up for longer periods the proportion of children with injuries increased, regardless of the diagnostic category at first admission. This is probably the effect of changing patterns of accidents with age (fig 1 ).

\section{DEATHS}

Of the 17724 children discharged alive from their first admission and followed up for one year from that admission, $11(0.06 \%)$ died. Six of these deaths were from causes not covered by the diagnoses in this study - that is, not accidents. Nineteen $(0.2 \%)$ of the 10889 children discharged alive with index admissions between 1976 and 1981 died within the five year follow up. Ten of these 19 had a cause of death with a 
diagnosis other than accident. We aim to study mortality in these cohorts further and report this later.

\section{Discussion}

Our data provide information, not readily available elsewhere, on numbers of children admitted to hospital because of accidents. The data complement routinely available statistics on numbers of episodes of accidents resulting in hospital admission available from the hospital inpatient enquiry ${ }^{16}$ and on deaths ascribed to accidents in children available from the Office of Population Censuses and Surveys' mortality statistics. ${ }^{17}$ Our data show that admission for an accident is fairly common for a child: in the Oxford population, on average one child in 88 aged under 6 is admitted to hospital for an accident at least once each year. This is comparable with data from the 1970 British birth survey, in which on average each year about one child in 80 had an admission to hospital for an accident in the first five years of life. ${ }^{18}$ In our study, as elsewhere, ${ }^{19}$ admission rates for boys were a little higher than those for girls. Admission rates varied strikingly by age and, in particular, numbers of admissions for poisoning and burns peaked in children aged 2 years or less, and thereafter declined with age. There was a decrease over 1976-86 in admission rates for poisoning. Others have reported declines in hospital admission rates for poisoning and related it to the increased use of child resistant containers for drugs. ${ }^{2021}$ In principle it seemed possible that children, unable to open containers, might find other ways of causing accidental injuries to themselves. It was therefore interesting that the decline in poisoning was not counteracted by any substantial increase over time in admission rates for other types of accident.

Our data included only hospital admissions and did not cover accidents in the community as a whole. Studies of a different design are needed to investigate the full extent of childhood accidents in the population. ${ }^{182}$ Hospital admission rates are no doubt influenced by parental thresholds in seeking hospital care after accidents and by clinical thresholds in respect of whether to admit children. Thus, possibly the decline in admission rates over time identified by us might represent an increase in the threshold for admission. If this were so, however, it would have had to be selective to substantially influence our findingsthat is, the change would have had to apply to poisonings rather than accidents or burns. Similarly, different threshold levels for admission may to some extent influence the observed pattern of admission to hospital by age group and sex.

Our data were confined to admissions occurring in the six districts covered by the Oxford record linkage study. They therefore probably underestimated slightly the true incidence of hospital care for accidents in these children. Any migration out of the area would also result in a small underestimate of the level of repeat admissions. Also we excluded repeat admissions for accidents which occurred within 28 days of discharge from the index admission. We did so to try to exclude repeat admissions for the same accident, but we may also have excluded some admissions for new accidents shortly after the index episode.

The concept of "accident proneness" in children remains controversial, but our study shows that accidents, or hospital admissions for accidents, are not random occurrences in respect of children. It was not possible to analyse these data by social class, but others have shown that the chance of an injury is not random across all social classes..$^{18}$ In this study we also showed that the risk of further admissions varies with age. Associations with social class or age may to some extent explain the clustering observed. There do, however, appear to be some children who have had at least one hospital admission for an accident who are more likely than would be expected by chance to experience further admissions. Nevertheless, the number of children with multiple admissions is small on a population basis: in our study there were 22 children with three or more hospital admissions for accidents within a year in the total average resident population of 163000 children under the age of 6 years. It is, of course, important to reduce or eliminate all preventable accidents, and health education with this goal should be targeted both at the families of children in general and at those who have had at least one hospital admission for an accident.

The Unit of Clinical Epidemiology is part of the Department of Public Health and Primary Care, University of Oxford. The unit is funded by the Department of Health, and the Oxford record linkage study is funded by the Oxford Regional Health Authority. Dr Joyce Ferguson was supported through a postdoctoral fellowship from the National Health Research and Development Program (Canada). Data were extracted from the Oxford record linkage study files by Glenys Bettley. Statistical advice was provided by Valerie Seagroatt.

1 Department of Health and Social Security. Basic principles of child accident prevention: a guide to action. London: Department of Health, 1989. $(\mathrm{EL}(89) \mathrm{P} / 96$.)

2 Child Accident Prevention Trust. Basic principles of child accident prevention London: Child Accident Prevention Trust, 1989.

3 Department of Health. Children and roads - a safer way. London: Department of Health, 1990. (EL/M(90)1.)

4 National Association of Health Authorities. Action on accidents: the unique role of the health service. Birmingham: National Association of Health Authorities, 1990.

5 Bijur PE, Stewart-Brown S, Butler N. Child behaviour and accidental injury in 11966 preschool children. Am $f$ Dis Child 1986;140:487-92.

6 Bijur PE, Golding J, Haslum M, Kurzon M. Behavioural predictors of injury in school-age children. Am f Dis Child 1988;142:1307-12. Husband P. The accident-prone child. Practitioner 1973;211:335-44.

8 Eminson CJ, Jones H, Goldacre M. Repetition of accidents in young children. f Epidemiol Community Health 1986;40:170-3.

J Epidemiol Community Health 1986;40:170-3.
Boyce WT, Sobolewski S. Recurrent injuries in schoolchildren. Am $\mathcal{F}$ Dis Child 1989;143:338-42.

10 Bijur PE, Golding J, Haslum M. Persistence of occurrence of injury: can injuries of preschool children predict injuries of school-aged children? Pediatrics 1988;82:707-12

11 Rivara FP. Epidemiology of childhood injuries 1: review of current research and presentation of conceptual framework. Am $\mathcal{F}$ Dis Child 1982;136:
$399-405$.

12 Goldacre MJ, Simmons H, Henderson J, Gill LE. Trends in episode based and person based rates of admission to hospital in the Oxford record linkage study area. $B M \mathcal{F} 1988 ; 296: 583-5$.

13 World Health Organisation. Manual of the international statistical classification of diseases, injuries, and causes of death. 8th revision. Geneva: WHO, 1967.

14 World Health Organisation. Manual of the international statistical classification of diseases, injuries, and causes of death. 9th revision. Geneva: WHO, 1977.

15 Armitage P, Berry G. Statistical methods in medical research. 2nd ed. Oxford: Blackwell Scientific, 1987:371-4.

16 Office of Population Censuses and Surveys. Hospital in-patient enquiry. London: HMSO, annual.

17 Office of Population Censuses and Surveys. Mortality statistics. London: HMSO, annual.

18 Stewart-Brown S, Peters TJ, Golding J, Bijur P. Case definition in childhood accident studies: a vital factor in determining results. Int $\mathcal{f}$ Epidemiol 1986;15:352-60.

19 Rivara FP, LoGerfo JP. Epidemiology of childhood injuries II: sex differences in injury rates. Am J Dis Child 1982;136:502-6.

20 Jackson RH. Childhood poisoning: perspectives and problems. Hum Toxicol 1983;2:285-93

21 Jackson RH, Craft AW, Lawson GR, Beattie AB, Sibert JR. Changing patterns of poisoning in children. $B M \mathcal{J}$ 1983;287:1468

22 Agass M, Mant D, Fuller A, Coulter A, Jones L. Childhood accidents: a practice survey using general practitioner records and parental records. British fournal of General Practice 1990;40:202-5.

(Accepted 5 October 1990) 